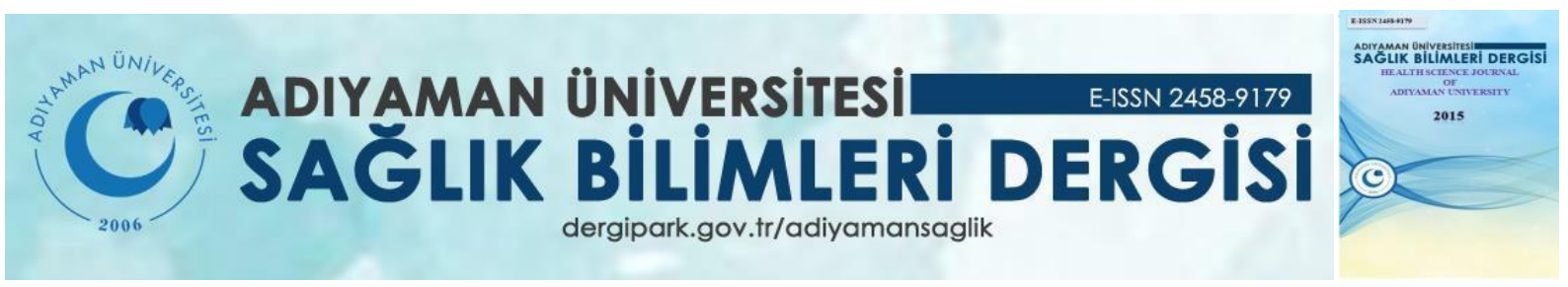

Araştırma/Research

\title{
İkinci ve Üçüncü Trimester Gebelerin Fiziksel Aktivite Düzeyi ve Fiziksel Aktivite Engelleri
}

\section{Zeynep DAŞIKAN ${ }^{1}$, Özlem GÜNER ${ }^{2}$, Tuğçe BOZKURT ${ }^{3}$}

\author{
${ }^{1}$ Ege Üniversitesi Hemşirelik Fakültesi, Hemşirelik Bölümü, Kadın Sağlığı ve Hastalıkları Hemşireliği Anabilim Dalı, \\ Bornova/ İzmir Türkiye / ORCID ID: 0000-0002-0933-9647 \\ ${ }^{2}$ Sinop Üniversitesi Sağlık Yüksekokulu, Ebelik Bölümü, Sinop Türkiye / ORCID ID: 0000-0002-8302-9073 \\ ${ }^{3}$ Babaeski Devlet Hastanesi Acil Servis Hemşiresi, Babaeski/Kırklareli Türkiye / ORCID ID: 0000-0003-1792-2864
}

ÖZ

Amaç: Gebeliğin ikinci ve üçüncü trimestirinde olan sağlıklı gebe kadınların fiziksel aktivite düzeyi ve engelleri ile etkileyen faktörlerin belirlenmesi amaçlanmıştır.

Gereç ve Yöntem: Araştırma tanımlayıcı ve kesitsel niteliktedir. Çalışma Şubat-Mayıs 2016 tarihleri arasında İzmir de kamusal bir üniversite hastanesinin gebe izlem polikliniğine başvuran ve sağliklı 246 gebe ile yürütülmüş̧ür. Verilerin toplanmasında Tanıtıcı Özellikler Formu, Fiziksel Aktivite Engelleri Formu ve Egzersiz Davranışları Anketi (EDA) kullanılmıştır. Verilerin analizinde; spearman korelasyon analizi, kruskal-wallis varyansı ve mann-whitney U testi kullanılmıştır

Bulgular: Araştırmaya katılan kadınların yaş ortalaması $27.85+4.01$ ve gebelik haftası ortalaması 26.33+3.69'dur. Kadınların \%78'i gebelik öncesi Fiziksel Aktivite algısını aktif ifade etmiş, gebelikte ise bu oran Egzersiz Davranışları Anketine göre \%54.1'i aktif olarak saptanmıştır.Araştırmaya katılan gebe kadınların en fazla yaşadıkları fiziksel aktivite engelleri sırasıyla; motivasyon/ istek eksikliği (\%50.4), bilgi eksikliği (\%32.5) zaman yokluğu (\%30.1), aile/eş desteğinin olmaması (\%28.5) uygun olmayan hava koşulları (\%26) ve bir işte çalışmak (\%24) olarak belirlenmiştir. Gelir durumu düşük olan, çekirdek ailede yaşayan, multigravida, plansız gebeliği olan ve gebelik öncesi aktivitesini hareketsiz algılayan kadınların Egzersiz Davranışları Anketi medyan değeri yüksek saptanmıştır $(\mathrm{p}<0.05)$.

Sonuç: Gebe kadınların yaklaşık yarısı inaktifdir. Fiziksel aktivite yapmadaki engellerin başında motivasyon eksikliği gibi kişisel engeller yer almaktadır. Sağlık profesyonelleri gebe kadınlara, fiziksel aktivite ve yararları hakkında danışmalık yapmalı ve davranışa dönüştürmesi konusunda destekleyici olmalıdır.

Anahtar kelimeler; Gebelik, fiziksel aktivite, egzersiz, yararları, engeller, prenatal bakım.

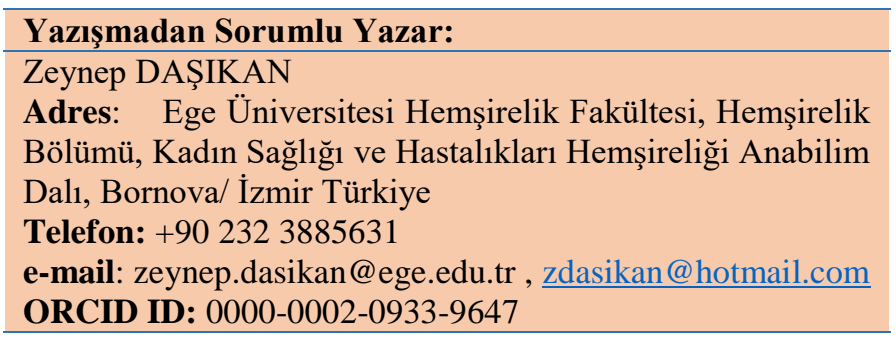

\section{Doi: 10.30569.adiyamansaglik.643369}

Geliş Tarihi : 05.11.2019

Kabul Tarihi : 16.11.2019

Atıf Gösterimi/How to Cite: Daşıkan Z, Güner Ö, Bozkurt T. İkinci ve Üçüncü Trimester Gebelerin Fiziksel Aktivite Düzeyi ve Fiziksel Aktivite Engelleri. Adıyaman Üni. Sağlık Bilimleri Derg. 2019; 5(3); 1731 -1745. doi: 10.30569.adiyamansaglik.643369. 


\section{Physical Activity Level and Barriers of Second and Third Trimester Pregnant Women}

\section{ABSTRACT}

Aim: The aim of this study was to determine the physical activity level and barriers, the factors affecting them of healthy pregnant women in the second and third trimesters of pregnancy.

Material and Method: The research was descriptive and cross-sectional. The study was carried out with 246 healthy pregnant women at the antenatal care of a public university hospital in İzmir between February-May 2016. Descriptive Characteristic Form, Physical Activity Barriers Form and Leisure-Time Physical Activity Questionnaire (LTPA) was used for data collect. The analysis of data was analyzed by Spearman Correlation, Kruskal-Wallis Variance, and MannWhitney U test.

Result: The women age mean in the study was $27.85+4.01$. Women participating in our study were expressed as active $78 \%$ of the physical activity perception before pregnancy and this rate was declared as active $54.1 \%$ in pregnancy according to Leisure-Time Physical Activity Questionnaire Physical activity barriers experienced by the participants were as follows; lack of motivation / request (50.4\%), lack of information (32.5\%), lack of time (30.1\%), lack of family / spouse support (28.5\%), inappropriate weather conditions (26\%) and working life (24\%). Leisure-Time Physical Activity Questionnaire median values were statistically significantly increased in women with low-income status, living in nuclear family, having multigravida, having an unplanned pregnancy and perceived motionless the activity before pregnancy.

Conclusion: About half of pregnant women are inactive. Personal barriers such as lack of motivation are the main obstacles in physical activity. Health professionals should advise pregnant women about the physical activity and benefits, and motivate them to do.

Key Words: Pregnancy, physical activity, exercise, benefits, barriers, prenatal care.

\section{GİRIȘ}

Gebelikte yapılan düzenli fiziksel aktivite (FA) annenin ve fetüsün sağlı̆̆ını ve gelişimini olumlu açıdan etkilemektedir $(1,2,3)$. Gebelikte yapılan düzenli FA/egzersiz; gebelik için risk teşkil eden aşırı gestasyonel kilo alımı (GKA), gebelikte hipertansif hastalıklar, gestasyonel diyabetus mellitus (GDM), sezaryen doğum, varis, derin ven trombozu, gebelik şikayetleri (yorgunluk, bacaklardaki ödem, bel ağrısı, bacak krampları), fetal makrozomi ve nöral tüp defekti gibi durumların gelişme riskini azaltmaktadır. Ayrıca doğum süresini ve doğuma bağlı 
komplikasyonların gelişmesini azaltmaktadır. Gebelik ve postpartum dönemde yapılan FA'nin; uyku problemleri, stres, anksiyete ve depresyon gibi psikolojik durumların gelişimini azalttı̆ğ, kadınların beden imaji, kendine olan güveni ve zindeliğini artırdığg belirlenmiştir $(6,8,9)$. Bu nedenle, düzenli FA sağlıklı gebe kadınlar ve asgari riskleri olan kadınlar için gebelik k1lavuzlarında önerilmektedir(1,10). US Department of Health and Human Services (HHS), "Sağlıklı bir gebe, gebelik süresince ve doğumdan sonra haftada en az 2.5 saat orta yoğunlukta FA ve aerobik yapmalıdır” şeklinde bildirmiştir. İlk trimesterde bulantı, kusma ve yorgunluk yakınmaların sık görülmesi nedeniyle FA başlangıcı açısından en uygun zaman ikinci trimesterdir(3,4). Gebelikte FA'nin yararlarına rağmen, birçok kadın yeterince aktif değildir(11). Literatür, pek çok gebenin FA'nin hiçbir formunu uygulamadığını, ev ve uğraş faaliyetleri de dahil olmak üzere aktivite seviyelerini azaltma eğiliminde olduklarını göstermektedir(12-14). Gebelikte FA'yi etkileyen faktörler incelendiğinde; kişisel nedenler (tutum, inanç, bilgi ve kişilik özellikleri), gebelikte yaşanan şikayetler, kişilerarası ve sosyal etkiler (aile, arkadaşlar), kültürel normlar ve çevresel etmenler (fiziksel/ sosyal çevre, toplum, hava durumu) gibi özelliklere atıfta bulunulmuştur (12-14). Sosyo-demografik faktörler arasında, düşük eğitim düzeyi, gelir ve evde artan çocuk sayısı azalan FA ile en fazla ilişkili olanlardır(1,12). FA'ye engel olan çok çeşitli faktörler vurgulanmışsa da asıl engelin kişisel problemler olduğu sonucuna varılmıştır(14,15).

Gebelikte hareketsiz yaşam tarzının maternal-fetal sağlık üzerine olan risklerini azaltmak amacıyla, kadınların gebelikte FA seviyesini engelleyen faktörlerin belirlenmesi ve bunlara yönelik yapılacak etkili girişimlerin geliştirilmesi son derece önemlidir. $\mathrm{Bu}$ çalışmada; gebeliğin ikinci ve üçüncü trimestirinde olan sağlıklı gebelerin FA seviyeleri ve FA engelleri, etkileyen faktörlerin belirlenmesi amaçlanmıştır.

\section{GEREÇ VE YÖNTEM}

Araştırmanın tipi: Bu araştırma tanımlayıcı ve kesitsel niteliktedir.

Evren ve Örneklem: Araştırma; Şubat-Mayıs 2016 tarihleri arasında İzmir de kamusal bir üniversite hastanesinin Kadın Hastalıkları ve Doğum Anabilim Dalı'na bağlı gebe izlem polikliniğine başvuran sağlıklı gebe kadınlarda yapılmıştır.

Katılımcı Kriterleri: Gebeliğin ikinci ve üçüncü trimestirinde (20.-36. gebelik haftası) olan, 19 yaş üstü, spontan sağlıklı tek gebeliği olan, egzersiz yapmaya fiziksel ve psikolojik bir engeli olmayan, riskli gebeliği olmayan (kalp, hipertansiyon, kanama, erken doğum tehdidi) iletişim sorunu olmayan ve araştırmaya katılmaya gönüllü olan gebe kadınlar örnekleme alınmıştır. 
Araştırmanın örnekleminde; araştırmacı haftanın belirli bir günü hastanenin gebe izlem polikliniğginde bulunmuş, araştırma kriterlerine uyan gebeler ile yüz yüze görüşme yöntemi ile araştırma verilerini toplamıştır. Araştırma sürecinde toplam 430 gebe ile karşılaşılmıştır. $\mathrm{Bu}$ gebelerden birinci trimesterde olan (84 kişi), riskli gebelik (70 kişi) ve araştırmaya katılmayı kabul etmeyen (30 kişi) toplam 184 gebe kadın araştırma dışı kalmıştır. Araştırmaya dahil edilme ölçütlerini karşılayan toplam 246 gebe çalışmaya dahil edilmiştir.

\section{Veri Toplama Araçları}

Araştırma verilerinin toplanmasında Tanıtıcı Özellikler Formu, Fiziksel Aktivite Engelleri Soru Formu ve Egzersiz Davranışları Anketi (EDA) kullanılmıştır.

Tanıtıcı Özellikler Formu: $\mathrm{Bu}$ form araştırmacılar tarafindan literatür doğrultusunda hazırlanmıştır. Formda, katılımcıların fiziksel ve bireysel özellikleri (kilo, boy, ağırlık artışı, gebelik haftası, yaş, eğitim düzeyi, çalışma durumu vs) obstetrik özellikleri, ve sağlık personelinden gebelikte FA ile ilgili bilgi alma durumunu içeren sorulardan oluşmuştur $(1,3,7,8)$.

Fiziksel Aktivite Engelleri Formu: Sosyal ekolojik perspektifler, davranışın çok sayıda faktörden etkilediğini vurgulamaktadır $(7,8,13-15)$. Sosyo-ekolojik çerçeve, çoklu faktörleri ve bu faktörler arasındaki ilişkilerini dikkate alarak çok yönlü kapsamlı bir sağlığ 1 geliştirme modelidir(14,15). Gebelikte FA engellerini araştırmak üzere birçok nitel ve nicel araştıma yapılmıştır. Yapılan bu çalışmalarda kadınların FA engelleri sosyo ekolojik çerçeve doğrultusunda kişisel(örn; fiziksel, psikolojik), kişilerarası (örn; aile, arkadaşlar, sağlık profesyonelleri, sosyal ve kültürel etkiler), çevresel (örn; tesislere erişim, çevre ve hava koşulları, politikalar, maliyet, toplum) ele alınmıştır. Yapılan nicel ve nitel araştırmalardan yararlanılarak sosyoekolojik çerçeve doğrultusunda evet /hayır şeklinde 15 adet FA engel sorusu hazırlanmıştır. Bu taslak soru formu için bu alanda uzman üç kişiden görüş alınmış, daha sonra 10 gebe kadında ön uygulaması yapıldıktan sonra gerekli düzenlemeler yapıldıktan sonra 12 soru olarak son halini almıştır.

Egzersiz Davranışları Anketi (EDA): Godin ve Shephard tarafından bireylerin boş zaman aktivitelerini ölçmek için geliştirilen Boş zaman egzersiz anketi (LTPA), basit bir ölçme aracıdır (16). Anket dört soru içermektedir. Bir hafta boyunca günlük yapılan yorucu/ağır, orta ve hafif dereceli aktivite sayısını bildirmekte ve bir hafta boyunca boş zamanlarda yapılan aktiviteleri 15 dakikadan fazla olmak üzere ne sıklıkla (sık sık, ara sıra, az veya hiç) yaptığını sorgulamaktadır. Ölçeğin Türkçe geçerliliği Sarı ve Erdoğan tarafından yapılmış ve Egzersiz 
Davranışları Anketi olarak adlandırılmıştır. Ölçeğin Cronbach alpha katsayısı 0.64 olarak bildirilmiştir(18). Bu çalışmada ölçeğin Cronbach alpha katsayısı 0.81 olarak saptanmıştır. Egzersiz Davranışları Anketi’ne göre fiziksel aktivite/egzersizler: (1) Yorucu/ağır (2) orta (3) hafif derece olarak üç alt grupta toplanmıştır. Yorucu /ağır fiziksel aktivite/egzersizler: koşu, futbol, basketbol, judo, joking ve koşu, bisiklete binme, tempolu yüzme, aerobik, ağırlık kaldırma, kayak, toprak çapalama, kumsalda yürüme. Orta derece/yorucu olmayan fiziksel aktivite/egzersizler: hızlı tempoda yürüyüş, tenis, voleybol, hafif yüzme, dans etme, folklor, bahçe işleri, hafif ağırlıklarla çalışma, araba yıkama ve cilalama, pencereleri ve yerleri temizleme, ip atlama, merdiven çıkma. Hafif derecede fiziksel aktivite/egzersizler: balık tutma, hafif tempoda yürüyüş, bowling, ata binme, camları silme, ütü yapma ve masa tenisi vs. aktivitelerini içermektedir $(16,17)$.

EDA Skorunun Hesaplaması: Ankette bireylerin fiziksel aktivite/egzersiz puanları hesaplanırken, Godin Egzersiz Anketi'nin( LTPA) puan hesaplamasından yararlanılmıştır. Hesaplamada metabolik değer(MET)-dakika olarak bir skor elde edilmektedir. Bir METdakika; yapılan aktivitenin sıklığı ile MET skorunun çarpımı hesaplanmaktadır. Haftalık yorucu, orta ve hafif aktivite sıklıkları sırasıyla dokuz, beş ve üç ile çarpılır, bu üç değer, listelenen faaliyetlerin MET değer kategorilerine karşılık gelir. Haftalık $=(9 \mathrm{x}$ ağır $)+(5 \mathrm{x}$ orta $)+$ (3 x hafif ). Örneğin; Yorucu/ağır fiziksel aktivite/egzersizlerden birini haftada bir kez yapan gebe kadın için skor $9 \times 1=9$ puandır $(16,17)$. EDA toplam puanının artması FA düzeyinin artığının göstergesidir.

Verilerin Analizi: Araştırma verilerinin değerlendirilmesinde IBM-SPSS 23 yazılımı kullanılmıştır. Tanımlayıcı analiz için sayı, yüzde, ortalama, medyan, çeyrekler arası aralık (IR) değerleri kullanılmıştır. Numerik verilerin normal dağılıma uygunluğu Shapiro-Wilk ve Kolmogorv-Smirnov testiyle yapılmıştır. Parametrik olmayan verilerde spearman korelasyonu, kruskal-wallis varyans analizi ve mann-whitney U testleri kullanılmıştır. Anlamlılık düzeyi $\alpha=$ 0.05 olarak kabul edilmiştir.

Araştırmanın Etik Yönü: Araştırma için Bilimsel Etik Kuruldan (2016/30) etik izin, araştırma yeri için hastane yönetiminden yazılı izin alınmıştır. Katılımcılara araştırmanın amacı ve süresi hakkında bilgi verilerek kişisel yazılı onamları alınmıştır 


\section{BULGULAR}

Araştırmaya katılan kadınların yaş ortalaması $27.85 \pm 4.01$ dir. Gebe kadınların \%58.1'i ikinci trimesterde,\%41.9'u üçüncü trimesterde, \%65.4'nün gebelikte FA konusunda bilgisi olduğu belirlenmiştir. Gebelerin bireysel, fiziksel ve obstetrik özellikleri Tablo 1 de verilmiştir.

Tablo 1. Gebe Kadınların Bireysel ve Obstetrik Özellikleri ile Fiziksel Aktivite Durumlarının Karşılaştırması

\begin{tabular}{|c|c|c|c|c|c|}
\hline \multirow[t]{2}{*}{ Değişkenler (n: 246) } & \multirow[t]{2}{*}{ Gruplar } & \multicolumn{2}{|l|}{ Total } & \multirow{2}{*}{$\begin{array}{r}\text { Toplam EDA } \\
(\mathrm{M} ; \mathrm{IR})\end{array}$} & \multirow{2}{*}{$\begin{array}{l}\text { Analiz } \\
\mathbf{P}\end{array}$} \\
\hline & & n & $\%$ & & \\
\hline Gebelik haftası & T2 (20-27 hafta) & 143 & 58.1 & $81 ; 80$ & $.762^{\mathrm{a}}$ \\
\hline $\begin{array}{l}\text { (Ort/Ss: } \\
26.33 \pm 3.69 / \text { hafta })\end{array}$ & T3 (28-36 hafta) & 103 & 41.9 & $80 ; 70$ & \\
\hline Yaş grupları (Yıl) & 20-24 yaş & 49 & 19.9 & $81 ; 65$ & $.974^{\mathrm{b}}$ \\
\hline \multirow[t]{2}{*}{ (Ort/Ss 27.86 \pm 3.98$)$} & 25-29 yaş & 119 & 48.4 & $77 ; 88$ & \\
\hline & $30-40$ yaş & 78 & 31.7 & $85 ; 75$ & \\
\hline \multirow[t]{3}{*}{ Eğitim Durumu } & İlköğretim & 62 & 25.2 & $102 ; 72$ & $.098^{\mathrm{b}}$ \\
\hline & Lise & 108 & 43.9 & $85 ; 88$ & \\
\hline & Üniversite & 76 & 30.9 & $71 ; 53$ & \\
\hline \multirow[t]{2}{*}{ Çalışma Durumu } & Çalışan & 81 & 32.9 & $82 ; 82$ & $.214^{\mathrm{a}}$ \\
\hline & Çalışmayan & 165 & 67.1 & $80 ; 76$ & \\
\hline \multirow[t]{3}{*}{ Gelir Durumu } & Düşük & 73 & 29.7 & $118 ; 72$ & $<.000^{b}$ \\
\hline & Orta & 143 & 58.1 & $71 ; 60$ & \\
\hline & Çok iyi & 30 & 12.2 & $74 ; 46$ & \\
\hline \multirow[t]{2}{*}{ Aile Tipi } & Çekirdek Aile & 184 & 74.8 & $93 ; 86$ & $.003^{a}$ \\
\hline & Geniş Aile & 62 & 25.2 & $72 ; 45$ & \\
\hline Gebelik sayısı & 1 & 113 & 45.9 & $75 ; 67$ & $.039^{a}$ \\
\hline
\end{tabular}




\begin{tabular}{|c|c|c|c|c|c|}
\hline & $\geq 2$ & 133 & 54.1 & $93 ; 86$ & \\
\hline Gebeliği Planlama & Evet & 164 & 66.7 & $74 ; 55$ & $<.000^{\mathrm{a}}$ \\
\hline Durumu & Hayır & 82 & 33.3 & $115 ; 80$ & \\
\hline Gebelik Öncesi & Aktif & 192 & 78.0 & $75 ; 67$ & $.012^{a}$ \\
\hline FA Algısı & Hareketsiz & 54 & 22.0 & $113 ; 92$ & \\
\hline Gebelikte FA Eğitim & Evet & 161 & 65.4 & $86 ; 79$ & $.236^{\mathrm{a}}$ \\
\hline Alma Durumu & Hayır & 85 & 34.6 & $76 ; 68$ & \\
\hline & & $\mathbf{M e}$ & & & \\
\hline
\end{tabular}

\begin{tabular}{lllll}
\hline Gebelik başlangıç & $16,9-29.8$ & $22.69 \pm 2.33$ & $.220^{* *}$ & $.001^{\mathrm{r}}$ \\
BKİ & & & & \\
$\left(\mathbf{k g} / \mathbf{m}^{\mathbf{2}}\right)$ & & & & \\
\hline Gebelikte ağırlık & $(-8)(+20)$ & $7.67 \pm 3.47$ & $-.206^{* *}$ & $.001^{\mathrm{r}}$ \\
artışı $/ \mathbf{K g}$ & & & & \\
\end{tabular}

T2 : Trimester 2, T3 : Trimester 3, r: Spearman korelasyon, M: medyan, IR( interquartile range), ${ }^{\mathrm{a}}$ Mann whitney $\mathrm{U}$ testi, ${ }^{\mathrm{b}}$ Kruskal wallis, $\quad * * . \mathrm{P}<0.001$

Araştırmaya katılan gebelerin EDA ölçeğine göre; yorucu (ağır), orta, hafif ve toplam FA puan ortalamaları (MET-dk/hafta) ve medyan değerleri Tablo 2'de verilmiştir. Gebelerin en yüksek FA düzeyinin orta şiddette (M: 45;36) MET-dak/hafta) olduğu belirlenmiştir. EDA'ya göre haftalık yapılan ağır, orta ve hafif şiddette aktivitelerin 15 dakikadan fazla olmak üzere ne sıklıkla yaptığı sorulduğunda ise gebelerin \%48.4'ü ara sıra, \%45.9 hiç veya nadiren, \%5.7'si sık sık olarak belirtmiştir. EDA ölçeği FA türlerinden en fazla yapılanlar ise; yorucu FA' den aerobik(\%47.6), orta dereceli FA'den evi temizlemek/yerleri silmek(\%87.8), merdiven çıkmak(\%84.1), hızlı tempoda yürüyüş(\%36.2), hafif dereceli FA'de ise ütü yapmak (\%93.9), hafif tempoda yürüyüş (\%81.7) olarak saptanmıştır (Tablo 2). 
Tablo 2. Gebe Kadınların Fiziksel Aktivite (FA) Düzeyleri ve Türleri

\begin{tabular}{lcc}
\hline EDA Alt Grup Puan Ort. (N:246) & Ort. \pm ss & Medyan; IR \\
\hline Yorucu /Ağır FA (MET-dak/hafta) & $26.34 \pm 28.78$ & $18 ; 27$ \\
\hline Orta FA (MET-dak/hafta) & $49.81 \pm 31.61$ & $45 ; 36$ \\
\hline Hafif FA (MET-dak/hafta) & $20.59 \pm 12.19$ & $18 ; 18$ \\
\hline Toplam FA (MET-dak/hafta) & $96.67 \pm 59.70$ & $80 ; 76$ \\
\hline FA Yapma Sıklıkları & N & $\%$ \\
\hline Sık Sık & 14 & 5.7 \\
\hline Ara Sıra & 119 & 48.4 \\
\hline Hiç veya Nadiren & 113 & 45.9 \\
\hline EDA Göre FA Türleri & & \\
\hline
\end{tabular}

\begin{tabular}{lcc}
\hline Şiddetli FA & & \\
\hline Koşmak & 29 & 11.8 \\
\hline Aerobik & 117 & 47.6 \\
\hline Kumsalda/Sahilde/ Yürümek & 78 & 31.7 \\
\hline Orta Dereceli FA & & \\
\hline
\end{tabular}

\begin{tabular}{lcc}
\hline Hızlı Tempoda Yürüyüş & 89 & 36.2 \\
\hline Hafif Yüzmek & 44 & 17.9 \\
\hline Hafif Toprak /Bahçe İşleri & 33 & 13.4 \\
\hline İş Yerinde Hareket Halinde Çalışmak & 57 & 23.2 \\
\hline Evi Temizlemek-Yerleri Silmek & 216 & 87.8 \\
\hline Merdiven Çıkmak & 207 & 84.1 \\
\hline Çocuklarla Oyun Oynamak & 46 & 18.7
\end{tabular}

\section{Hafif Derece FA}

\begin{tabular}{lcc}
\hline Hafif Tempoda Yürüyüş & 201 & 81.7 \\
\hline Camları Silmek & 149 & 60.6 \\
\hline Ütü Yapmak & 231 & 93.9
\end{tabular}

*EDA: Egzersiz Davranışları Anketi 
Araştırmaya katılan gebelerin en fazla yaşadıkları FA engelleri sırasıyla; kişisel engellerden motivasyon/ istek eksikliği (\%50.4), zaman yokluğu(\%30.1) kişilerarası engellerden FA'nin yararları hakkında bilgi eksikliği (\%32.5), aile/eş desteğinin olmaması(\%28.5), bir işte çalışmak (\%24), çevresel engellerden ise uygun olmayan hava koşulları (\%26) olarak belirlenmiştir (Tablo 3).

Tablo 3. Gebe Kadınların Fiziksel Aktivite Engelleri

\begin{tabular}{|l|l|l|l|}
\hline Engeller ( N: 246) & n & \% \\
\hline Kişisel (Intrapersonal) & 124 & 50.4 \\
\hline Motivasyon/istek eksikliği & 74 & 30.1 \\
\hline Zaman yokluğu & & \\
\hline FA yapmaktan hoşlanmamak & 53 & 21.5 \\
\hline Fiziksel rahatsılıklar* & 18 & 7.3 \\
\hline FA sonrası gebelik şikâyetlerinin artması** & 18 & 7.3 \\
\hline Kişilerarası (Interpersonal) & & \\
\hline FA'nin yararları konusunda bilgi eksikliği & \multicolumn{2}{|l|}{} \\
\hline Aile/eş desteğinin olmaması & 80 & 32.5 \\
\hline Bir işte çalışmak (işten geç çıkmak, yoğun çalışmak) & 59 & 24.0 \\
\hline FA yapacak kimsenin olmaması & 70 & 28.5 \\
\hline FA kıyafetleriyle görünmekten utanmak & 30 & 12.2 \\
\hline FA yapacak yerin olmaması & 6 & 2.4 \\
\hline & \multicolumn{2}{|l}{} \\
\hline
\end{tabular}

*Gebelikte yaşanılan fiziksel rahatsızlıklar (bulantı-kusma, ayaklarda şişme, kramp, yorgunluk, uykusuzluk, kanama, enfeksiyon geçirme vs.)

** FA/Egzersiz sonrası bel ağrısı, yorgunluk eklemlerde ağrı gibi gebelik şikâyetlerinin artması 
Gelir durumu düşük olan, çekirdek ailede yaşayan, multigravida olan, plansız gebeliği olan ve gebelik öncesi FA'sini hareketsiz algılayan kadınların FA düzeyi yüksek saptanmış ve aralarında istatistiksel olarak anlamlı bir ilişki bulunmuştur $(\mathrm{p}<0.05)$, (Tablo 1). Gebe kadınların FA düzeyleri ile gebelikte ağırlık artışı arasında negatif yönlü, gebelik başlangıç BKI ortalaması ile pozitif yönlü korelasyon ilişkisi saptanmıştır $(\mathrm{p}<0.01)$. Bunun sonucu olarak gebelikte ağırlık artışı ortalaması yüksek olan $(\mathrm{p}<0.001)$ ve gebelik başlangıç BKI ortalaması düşük olan kadınların FA yapma sıklığı düşük bulunmuştur ( $<<0.05)$, (Tablo 1).

\section{TARTIŞMA}

Yapılan çalışmalar sonucu gebelikte yapılan FA/egzersizin, GDM, gebelikte hipertansif hastalıklar gestasyonel kilo alımı, iri bebek (makrozomi) ve sezaryen doğumu önemli ölçüde azaltığı, vajinal doğum oranını artırdığı bulunmuştur. Ayrıca, gebelikte alınan kiloların doğum sonu verilmesine yardımcı olması, gebelik öncesi aktivitelerine geri dönmesi ve egzersiz kapasitesinin artmasına yardımcı olur $(1,5,9,14)$. Hareketsiz yaşam tarzı olan kadınların doğumda hastanede kalış süresi, perineal laserasyonların artması ve vajinal operatif doğum ve postpartum kilo retansiyonu artmaktadır(17).

Amerikan Spor Hekimliği Derneği (ACSM) ve Amerikan Obstetri ve Jinekoloji Derneği (ACOG) obstetrik veya tıbbi problemi olmayan gebe kadınların gebe olmayan kadınlarla eşit düzeyde günde en az 30 dakika orta şiddette haftada en az üç kez fakat tercihen beş kez, FA/egzersiz yapmalarını önermektedir $(1,14,21)$.

Gebelikte FA rehberlerine rağmen çoğu gebe kadın haftada en az 150 dakika orta şiddette FA önerilerine ulaşmamaktadır $(1,21)$. Çalışmada kadınların \%78'i gebelik öncesi FA algılarını aktif olarak ifade etmiştir. Gebelikte ise bu oran EDA ölçeğine göre \%54.1'i aktif olarak saptanmıştır. Gaston ve Vamos (2013) tarafından Kanada'da yapılan 623 gebe kadını içeren çalışmada kadınların \%85.2'si boş zamanlarında FA yaptıklarını bildirmişlerdir (12). Ancak literatürde; kadınların herhangi bir aktivitedeki (yoğunluğa veya süreye bakılmaksızın) değişiklikleri inceleyen çalışmalarda, gebelik öncesine göre gebelikte FA oranında azalma olduğunu bildirilmiştir. Yapılan çalışmalarda; gebe kalmadan önce FA yaptığını bildiren kadınların oranı, \% 63 ile \% 87.4 arasında olduğu bildirilmiştir. Gebelikte bu oranın aralığ önemli ölçüde genişleyerek \%38-78.4'ünün gebelik sırasında aktif olduğu bildirilmiştir $(11,22,23)$. Yüzme, tempolu yürüyüş, koşma, yoga, pilates gebelikte güvenli ve faydalı egzersiz türleridir(1,14,19). Gebelikte FA/egzersizin faydalarından yararlanmak için, ilk trimesterde başlatılmalı ve her biri doğuma kadar 30-60 dakikalık seanslar için haftada 3-4 kez 
sürdürülmelidir (19). Fakat yapılan birçok çalışmada olduğu gibi kadınların gebelik sürecinde ev işleri, günlük yaşam aktiviteleri de dahil olmak üzere hareketsiz kalmayı tercih ettikleri ve ayrıca orta şiddetteki aktivitelerini gebelik sürecinde hafif şiddette veya hareketsiz aktivitelerle değiştirmekte oldukları bildirilmiştir $(1,24,25)$. Bu çalışma gebe kadınların ev temizliğgi, merdiven çıkma, ütü yapma gibi ev işleri faaliyetleri ile ve hafif tempoda yürüyüş aktivitelerini yapma düzeyi yüksek bulunmuş, düzenli ve planlı orta şiddette FA türlerini yapma düzeyi düşük saptanmıştır.

Çalışmamızda; gebelikte FA düzeyini etkileyen faktörler incelendiğinde; gelir durumu düşük olan, çekirdek ailede yaşayan, multigravida olan, plansız gebeliği olan ve gebelik öncesi FA'sini hareketsiz algılayan kadınların EDA düzeyi yüksek saptanmış ve aralarında istatistiksel olarak anlamlı bir ilişki bulunmuştur $(\mathrm{p}<0.05)$. Gelir durumu düşük olan kadınların ev-bahçe işleri ile uğraşması, multipar kadınların diğer çocuklarla ilgili bakım ve sorumluluklarının olması nedeniyle aktivite oranı yüksek olabileceği düşünülmektedir. Ayrıca araştırmada kadınların üçte ikisi gebelikte FA konusunda bilgi sahibi olduğunu ifade etmiş fakat yaptıkları FA düzeyi ile ilişkili bulunmamıştır. Bu da kadınların FA konusunda yüzeysel bir bilgi sahibi olduğu ve davranış değişiminde etkili olmadığını göstermektedir. Bulgularımızın aksine; Nascimento ve ark. (2015) tarafından yapılan 1279 kadını içeren çalışmada, sosyo-demografik faktörler arasında, düşük eğitim düzeyi, gelir ve evde artan çocuk sayısı azalan FA ile en fazla ilişkili olanlar olarak bildirilmiştir (1). Yine benzer olarak; Gaston ve Cramp (2011) tarafından 1986'dan 2009'a kadar yayınlanan makalelerin sistematik derlemesinde, gebelikte FA'ye daha fazla katılım ile ilgili faktörler; yüksek eğitim seviyesi, yüksek gelir düzeyi, evde başka çocuğun olmaması ve gebelik öncesi aktif olması olarak bildirilmiştir (11). Literatürde FA ile ilgili farklılığın çok olmasının nedeni; FA'yi değerlendirmede farklı ölçeklerin kullanılması veya FA'yi ölçen objektif ölçüm araçlarının (pedometer) kullanılmaması, sosyodemografik özellikler, gebelik döneminde yaşanan rahatsızlıklar, mevsimsel ve kültürel farklılıklardan kaynaklanabilir.

\section{Fiziksel Aktivite Engelleri}

Literatürde gebelikte FA'ye engel olan çok çeşitli faktörler vurgulanmışsa da asıl engelin kişisel engeller olduğu sonucuna varılmıştır. Bunlar; motivasyon ve zaman eksikliği; yorgunluk, gebelik rahatsızlıkları (bulantı, gebelik ilerledikçe artan kilo alımına bağlı ağrı ve rahatsızlıklar vs.), aktivitenin türü, yoğunluğu ile ilgili olarak gebelik ve bebeklerine yönelik güvenlik kaygıları daha az sıklıkta belirtilmiştir (7,8,13-15,26,27). Amerika'da 1535 gebe kadınla (27- 
30 gestasyon haftası) yapılan bir çalışmada FA engelin \%85'nin kişisel problemler olduğu tespit edilmiştir. $\mathrm{Bu}$ engellerin yaklaşık olarak üçte ikisinin de gebelikte yaşanan sağlık problemleri olduğu saptanmıştır (7).

Perinatoloji hekimlerinin \%70'i gebelik döneminde preterm doğum( PTD) için yatak istirahati önermektedir. Egzersiz yapan ile yapmayan kadınlar arasında PTD oranlarının benzer olduğu ve egzersizin özellikle PTD açısından gebelikte zararlı olabileceği düşüncesini de yok etmiştir. Aslında, gebelikte yatak istirahati veya azalmış aktivitenin venöz tromboembolizm, kemik demineralizasyonu riskini artırdığı vurgulanmıştır (19). Bu araştırmada gebe kadınlarda en fazla yaşanan kişisel engellerden sırasıyla motivasyon/ istek eksikliği, zaman yokluğu ve FA yapmaktan hoşlanmama saptanmıştır. Avustralya'da yapılan bir çalışmada \%45.7 'sinde çok yorgun olma \%18.24'ünün egzersizi çok rahatsız edici bulma (26); Amerika'da 1535 gebe ile yapılan bir çalışmada, \%24.6 'sının zaman yokluğu/iş ve sosyal çatışmalar/çok yoğun olma (7); Cramp ve Bray tarafından yapılan diğer bir çalışmada ise \%41'inin yorgun olma nedenlerini bildirmişlerdir (8). Kişisel engellerin başında motivasyon eksikliğinin gelmesi; gebelere özgü motivasyon sağlayacak ve gebelikte FA yapılması gerekliliğine inancı artıracak koşulların sağlanmasındaki eksikliklerden kaynaklanmaktadır. FA'nin anne ve çocuk sağlığına olan yararları bulgusu olumlu tutum ve davranış niyetini etkiler. Prenatal sağlık alanında çalışan özellikle ebe ve hemşirelerin, gebe kadınlara FA'nin potansiyel sağlık yararları hakkında eğitim ve danışmanlık yapması motivasyonlarını artırabilir. Ayrıca FA müdahalelerine motivasyonel görüşme, hedef belirleme, planlama, kendini izleme, hedefe ulaşmada ödüllendirme, davranış değişim aşamalarını izleme, sosyal destek, geri bildirim gibi davranış değiştirme tekniklerinin dahil edilmesinin gebelikte FA seviyesini artırdığı ve maternal ve fetal sonuçlar açısından yararlı olduğu bildirilmiştir. Özellikle kilolu ve obez kadınlar, GDM tanısı alanlar, GKA fazla olan kadınlarda düzenli FA girişiminin etkili olduğu saptanmıştır $(1,79,14)$.

Araştırmada gebe kadınların kişilerarası FA engelleri arasında en yüksek oranda FA ve yararları konusunda bilgi eksikliği ve aile/eş desteğinin olmaması saptanmıştır. Gebelikte FA'nin engellerine yönelik farklı etnik kökenlerden gelen kadınlarla yapılan 41 çalışmayı içeren sistematik derlemede (6771 katılımcı; nitel 20, nicel 14 ve karma 7 yöntem); FA için aileden veya arkadaşlardan sosyal destek eksikliği, bilgi eksikliği ve iş sorumlulukları en sık belirtilen kişilerarası engeller olarak saptanmıştır (14). Çalışmamızla benzer olarak; Coll ve ark (2017) yaptığı araştırmada gebelikte en fazla kişilerarası engellerden bilgi eksikliği ve sosyal destek eksikliği olduğunu bildirmiştir (27). Yapılan araştırma sonuçlarına göre kişiler arası FA engellerinden en fazla FA konusunda bilgi eksikliği ve sosyal destek eksikliği olduğu 
görülmektedir. $\mathrm{Bu}$ durum; prenatal bakımda FA yönelik yeterli eğitim ve danışmanlık yapılmadığ1 ve davranışı eyleme geçirecek arkadaş, çevre ve egzersiz gruplarının eksik olduğunu göstermektedir. Prenatal bakımda görev yapan sağlık profesyonellerinin gebelikte FA ve yararları konusunda gebelere danışmanlık yapması, egzersiz yapabileceği grup veya sınıflara yönlendirmesi engellerin aşılmasında önemli katkı sağlayabilir.

Bu çalışmada; çevresel FA engellerinden en fazla, uygun olmayan hava koşulları ve FA yapmak için uygun yerin olmaması belirtilmiştir. Yapılan araştırmalarda çevresel engellerden en fazla tesislere erişim eksikliği, olumsuz hava koşulları, FA yapacak uygun ve güvenli yerlerin olmaması, uygun fiyatlı egzersiz sınıflarının bulunmaması olarak belirlenmiştir $(1,14,15)$. Farklı kültürlerde ve toplumlarda yapılan bazı çalışmalarda farklı kişilerarası/sosyal engeller ve çevresel engeller belirlenmiştir (7,8,14). Dashti ve ark. (2014) tarafından İran'da yapılan bir çalışmada kadınların ev dışında egzersiz yapmasının kültürel olarak uygun olmadığı belirtilmiştir (13). Gebelere yönelik ücretsiz egzersiz gruplarının oluşturulması, açık ve kapalı FA alanlarının oluşturulması, ulusal medya aracılığı ile destek verilmesi, toplum temelli düzenlemelerin yapılması çevresel engellerin aşılmasına destek olabilir.

\section{SONUÇ}

Araştırma sonucuna göre; gebe kadınların yaklaşık yarısı (\%45.9) hareketsizdir. Gebe kadınlarda motivasyon/ istek eksikliği ve zaman yokluğu en fazla görülen kişisel engellerdir. Kişiler arası engellerden FA'nin yararları konusunda bilgi eksikliği ve sosyal destek eksikliği, çevresel engellerden ise uygun olmayan hava koşulları saptanmıştır. Hem hareketsiz yaşam tarzı hem de gebelikte fazla kilo alımı, gebelikte maternal ve fetal risklerin artmasına, uzun vadede ise maternal obezite ve çocukluk obezitesinin de gelişmesine katkı sağlar. Gebelik, sağlık davranışlarını geliştirmek için kadınların çaba göstereceği en uygun zamandır. $\mathrm{Bu}$ nedenle, sağlık profesyonellerinden özellikle hemşireler; gebe kadınlara rehberler 1şığında FA yararları konusunda bilgi vermeli, düzenli FA yapılması konusunda danışmanlık yapmalıdır. Prenatal bakım ve izlemlerde FA konusunda motivasyonel danışmanlık yapılması, davranış değiştirme tekniklerinin kullanılması durumunda engeller giderilebilir. Gebelikte düzenli FA gebelikte ideal kilo alımını ve doğum sonrasın da sağlıklı kilonun sürdürülmesine olanak sağlar. Gebelik başlangıcında obez kadınların sayısının gittikçe artması, anne ve bebek sağlığı üzerindeki olumsuz sonuçları nedeniyle gebelikte FA desteklenmelidir. Ayrıca; ülkemizde daha geniş populasyonlarda ve gebeliğe özgü FA anketi kullanılarak yapılacak çalışmalara ve FA' nin etkinliğini araştıran girişimsel çalışmalara yer verilmelidir 


\section{KAYNAKLAR}

1. Nascimento SL, Surita FG, Godoy AC, Kasawara KT, Morais SS. Correction: Physical Activity Patterns and Factors Related to Exercise during Pregnancy: A Cross Sectional Study. PLoS One [Internet] 15 Temmuz 2015 [kaynak $31 \quad$ Ocak 2019];10(7):e0133564. Available at: https://dx.plos.org/10.1371/journal.pone.0133564

2. Evenson KR, Barakat R, Brown WJ, Dargent-Molina P, Haruna M, Mikkelsen EM, vd. Guidelines for Physical Activity During Pregnancy: Comparisons From Around the World. Am J Lifestyle Med 2014;8(2):102-21.

3. Cioffi J, Schmied V, Dahlen H, Mills A, Thornton C, Duff M, vd. Physical activity in pregnancy: Women's perceptions, practices, and influencing factors. J Midwifery Women's Health 2010;55(5):455-61.

4. Prather H, Spitznagle T, Hunt D. Benefits of exercise during pregnancy. $P M \& R$ [Internet] 2012;4(11):84550. Available at: http://dx.doi.org/10.1016/j.pmrj.2012.07.012.

5. Daşıkan Z. Weight Gain in Pregnancy Do Pregnant Women Receive Correct Weight Gain Recommendation in Prenatal Care Ödemiş İzmir". Turkiye Klinikleri Journal of Gynecology and Obstetrics 2015: (25);32-38. DOI:10.5336/gynobstet.2014-41422

6. Downs DS, Chasan-Taber L, Evenson KR, Leiferman J, Yeo S. Physical Activity and Pregnancy. Res Q Exerc Sport [Internet] Aralık 2012 [kaynak 31 Ocak 2019];83(4):485-502. Available at: http://www.ncbi.nlm.nih.gov/pubmed/23367811

7. Evenson KR, Moos M-K, Carrier K, Siega-Riz AM. Perceived Barriers to Physical Activity Among Pregnant Women. Matern Child Health J [Internet]. 14 Mayıs 2009 [kaynak 31 Ocak 2019];13(3):364-75. Available at: http://link.springer.com/10.1007/s10995-008-0359-8

8. Cramp AG, Bray SR. A prospective examination of exercise and barrier self-efficacy to engage in leisuretime physical activity during pregnancy. Ann Behav Med 2009;37(3):325-34.

9. Hui A, Back L, Ludwig S, Gardiner P, Sevenhuysen G, Dean H, vd. Lifestyle intervention on diet and exercise reduced excessive gestational weight gain in pregnant women under a randomised controlled trial. Int $J$ Gynaecol Obstet 2012;119(1):70-7.

10. Nascimento SL, Surita FG, Cecatti JG. Physical exercise during pregnancy: A systematic review. Curr Opin Obstet Gynecol 2012;24(6):387-94.

11. Gaston A, Cramp A. Exercise during pregnancy: A review of patterns and determinants. J Sci Med Sport [Internet]. 2011;14(4):299-305. Available at: http://dx.doi.org/10.1016/j.jsams.2011.02.006

12. Gaston A, Vamos CA. Leisure-time physical activity patterns and correlates among pregnant women in Ontario, Canada. Matern Child Health J 2013;17(3):477-84.

13. Dashti S, Joseph HL, Esfehani AJ, Su TT, Latiff LA, Esfehani RJ. Perceived barriers to physical activity among Iranian women. World Applied Sciences Journal 2014;32(3):422-8.

14. Harrison AL, Taylor NF, Shields N, Frawley HC. Attitudes, barriers and enablers to physical activity in pregnant women: a systematic review. J Physiother 2018;64(1).

15. Joseph RP., Ainsworth BE., Keller C. \& Dodgson JE. Barriers to Physical Activity Among African American Women: An Integrative Review of the Literature, Women \& Health 2015; 55:6, 679-699, DOI: 10.1080/03630242.2015.1039184

16. Godin G, Shephard JH. Leisure-time Exercise Questionnaire. Med Sci Sport Exerc 1997;29 June Su:36-38.

17. Sarı E, Erdoğan S. Adaptation of the Godin Leisure-Time Exercise Questionnaire into Turkish: The Validity and Reliability Study. Advances in Public Health [Internet]. 2016;2016:1- 7. Available at: http://www.hindawi.com/journals/aph/2016/3756028. 
18. Seneviratne SN, McCowan LME, Cutfield WS, Derraik JGB, Hofman PL. Exercise in pregnancies complicated by obesity: Achieving benefits and overcoming barriers. Am J Obstet Gynecol April 2015;44249. http://dx.doi.org/10.1016/j.ajog.2014.06.009

19. Berghella V. Saccone G. Exercise in pregnancy. Am J Obstet Gynecol April 2017; 335-37, http://dx.doi.org/10.1016/j.ajog.2017.01.023

20. Mottola MF, Davenport MH, Ruchat SM, Davies GA, Poitras VJ, Gray CE, vd. 2019 Canadian guideline for physical activity throughout pregnancy. British Journal of Sports Medicine 2018.

21. American College of Obstetricians and Gynecologists (ACOG). Exercise during pregnancy and the postpartum period. ACOG Committee opinion. Number 267. ACOG Committee Obstetric Practice Obstet. Gynecol. 2002; 99(1):171-3.

22. Clarke PE, Gross H, Lecturer CP. Women's behaviour, beliefs and information sources about physical exercise in pregnancy. Midwifery 2004;133-41.

23. Wallace A, Boyer D, Dan A, Holm K. Aerobic exercise, maternal self-esteem, and physical discomforts during pregnancy. J Nurse Midwifery [Internet]. 12 Kasım 1986 [kaynak 10 Şubat 2019];31(6):255-62. Available at: https://linkinghub.elsevier.com/retrieve/pii/0091218286900340

24. Lynch KE, Landsbaugh JR, Whitcomb BW, Pekow P, Markenson G, Chasan-Taber L. Physical Activity of Pregnant Hispanic Women. 2012 [kaynak 10 Şubat 2019];43(4):434-439. Available at: https:/www.ncbi.nlm.nih.gov/pmc/articles/PMC3491652/pdf/nihms401964.pdf

25. Tavares J de S, Melo AS de O, Amorim MMR de, Barros VO, Takito MY, Benício MHD, vd. Padrão de atividade física entre gestantes atendidas pela estratégia saúde da família de Campina Grande - PB. Rev Bras Epidemiol [Internet]. Mart 2009 [kaynak 10 Şubat 2019];12(1):10-9. Available at: http://www.scielo.br/scielo.php?script=sci_arttext\&pid=S1415-790X2009000100002\&lng=pt\&tlng=pt

26. Duncombe D, Wertheim EH, Skouteris H, Paxton SJ, Kelly L. Factors related to exercise over the course of pregnancy including women's beliefs about the safety of exercise during pregnancy. Midwifery [Internet]. 2009;25(4):430-8. Available at: http://dx.doi.org/10.1016/j.midw.2007.03.002

27. Coll CVN, Domingues MR, Gonçalves H, Bertoldi AD. Perceived barriers to leisure-time physical activity during pregnancy: A literature review of quantitative and qualitative evidence. J Sci Med Sport 2017;20(1):17-25. 